\title{
Ecologists row over lobbying strategy
}

[WASHINGTON] Two letter-writing campaigns by ecologists intended to influence congressional action on the Endangered Species Act have touched off a heated debate about the advice scientists should give lawmakers.

Several authors of a letter sent in January to Senate sponsors of a bill to reauthorize the act (see Nature 391, 829; 1998) have criticized a second letter signed by the presidents of the Society for Integrative and Comparative Biology (SICB) and eight other scientific organizations, which ran as a full-page advertisement in The New York Times last month.

The SICB letter was organized by its conservation chairman, Fraser Shilling of the University of California at Davis, and takes a harder line on species protection than most of the scientists who advocate reform of the act. It calls for a complete ban on killing any endangered animal or plant, including the 'incidental takes' permitted for landowners who file habitat conservation plans.

Even though many conservationists worry that such plans are too inflexible, and sometimes based on inadequate science, they have become the primary means of setting aside privately owned land for conservation.

Frances James, a biologist at Florida State University who is leading a review of habitat conservation plans by the American Institute of Biological Sciences, was so upset with the Times advertisement that she persuaded half a dozen colleagues to sign a letter chastising the signatories of the Shilling letter. The latter include the presidents of the Ecological Society of America, the Botanical Society of America and the Entomological Society of America.

James wrote that their action was "causing consternation among many biologists who have been working with endangeredspecies issues". She described early drafts of Shilling's recommendations — which had been circulating among scientists for a year - as "counterproductive and naïve".

Challenging ten specific points, she wrote that the blanket opposition to "incidental takes' was "not scientifically valid", as it would prohibit valid conservation measures, such as the prescribed burning of habitat and control of invasive species. "We were sorry to see your letter in The New York Times, because it means that scientists will probably have to disagree in public about endangered species protection," she wrote.

Joining James were Gary Meffe of the University of Florida, Stuart Pimm of the University of Tennessee, and Peter Brussard and Dennis Murphy of the University of Nevada at Reno, all of whom signed the more moderate January letter to Senate leaders.

Murphy agrees that "we don't want a split in the scientific community". But he is not shy about criticizing the SICB letter which he says "reads like the Sierra Club [conservation lobby group] wrote it instead of a group of scientific societies". He says the James letter is "an attempt by those who are doing their homework on this issue to police themselves and their colleagues".

Shilling says the criticism has less to do with science than politics. He calls the dispute a "territorial battle" between scientists too quick to yield to property rights advocates in the reauthorization battle and those — like himself — who would first "figure out what the standards [for species recovery] are, and then go in with our armour girded". Murphy counters by saying it is "not logical to ask a Republican Congress to make the act more stringent by orders of magnitude".

Although no signatories of Shilling's letter have retracted their endorsement, the Ecological Society of America considered withdrawing just before publication, because of the 'incidental take' clause and other objections. Another society president who signed admits: "We may have been caught by not being experts in this area, and by just feeling in general that we wanted to support a good cause."

To some, the incident illustrates how organized advocacy still does not come naturally to many scientists. "Scientific societies weren't put together as lobbying organizations," says Murphy. Tony Reichhardt

\section{Telescope users win respite from mobile phone interference}

[WASHINGTON] Radioastronomers using the giant Arecibo telescope in Puerto Rico have won a promise from the owners of the Iridium satellite network to limit radio interference from the orbiting constellation for part of each day.

The agreement, which took five years to negotiate, guarantees eight hours of 'quiet' time from 22:00 to 6:00 Eastern time, during which time the Iridium system will not interfere with astronomical observations at the key frequency of $1612 \mathrm{MHz}$.

Arecibo officials hail the agreement as a good compromise. But other radioastronomers worry that the interference issue is only getting worse.

The frequency band used for Iridium's 'downlink' to portable telephones on the ground is very near the emission frequency of the hydroxyl molecule, one of the most common interstellar molecules (see Nature $380,569 ; 1996)$. Arecibo, the world's largest radio dish, is particularly suited to studying hydroxyl emissions, and some astronomers lobbied for unrestricted access to that band.

But, says Paul Goldsmith, director of Cornell University's National Astronomy and Ionosphere Center, which operates

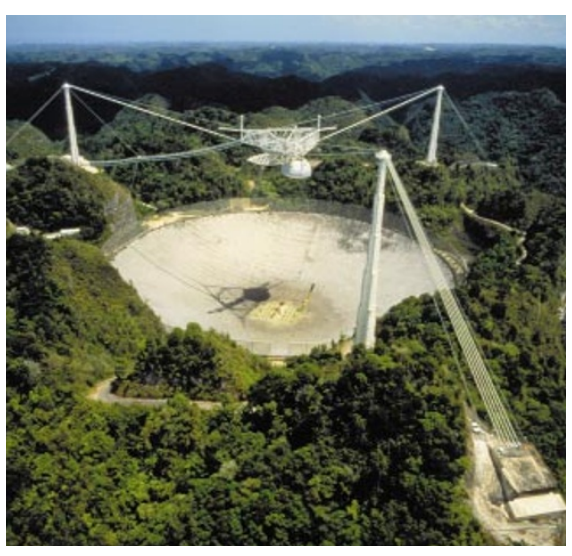

Quiet please: the Arecibo telescope will have eight hours 'peace' a day after agreement.

Arecibo, scientists got the best deal possible. "Some radioastronomers may have felt that they were entitled to 24 hours a day, but I'm happy that both sides could agree to eight," he said.

The Iridium system is scheduled to begin operation this autumn, providing telephone services to users around the world. Other proposed networks will not downlink at the same frequency, and so do not pose as big a threat to radioastronomy.
Organizations that rarely observe hydroxyl emissions have found it easier to solve the Iridium problem. The US National Radio Astronomy Observatory (NRAO) operates the Very Large Array in New Mexico and the Green Bank telescopes in West Virginia, and needs only four hours of quiet time a day. It signed an agreement with Motorola, Iridium's owner, several years ago.

European radioastronomers are working out their own agreement with Iridium, and it may be even more difficult to negotiate than the Arecibo pact. The Nançay telescope in France, for example, spends about half its time studying hydroxyl emissions, and may need more than an eight-hour quiet period.

Tomas Gergely, who handles spectrum management issues for the US National Science Foundation, says each observatory has its own needs, which makes it difficult to work out a blanket agreement between satellite operators and the astronomy community as a whole.

In general, though, scientists face an uphill battle as more satellite systems like Iridium come online. "We must be very vigilant so that radioastronomy as a discipline survives," says Gergely. 